\title{
Hemşirelik 1. ve 4. Sınıf Öğrencilerinin Yaşlı Ayrımcılığına İlişkin Tutumları
}

\author{
DOI: $10.26466 /$ opus.337355
}

\begin{abstract}
Alihan Olak ${ }^{*}$ Adile Tümer
*Hemşire, Kartal Koşuyolu Yüksek İhtisas Eğitim ve Araştırma Hastanesi, İstanbul / Türkiye E-Posta: alihanolak.ao@gmail.com

ORCID: 0000-0001-7564-0959

** Dr. Öğr. Üyesi, Muğla Sıtkı Koçman Üniversitesi, Sağlık Bilimleri Fakültesi, Muğla / Türkiye

E-Posta: tadile@mu.edu.tr

ORCID: 0000-0002-3078-6468
\end{abstract}

\section{Öz}

Bu araştırma, hemşirelik 1. ve 4. sını öğrencilerinin yaşlı ayrımcıllğına ilişkin tutumlarının incelenmesi amacıyla yapılmıştır. Tanımlayıcı tipte tasarlanan bu çalışma Kasım 2015-Mart 2016 tarihlerinde Muğla Sıtkı Koçman Üniversitesi'nde, 233 öğrencinin katılımı ile gerçekleştirilmiştir. Veriler sosyo-demografik form ve Yaşlı Ayrımcılığı Tutum Ölçeği (YATÖ) ile sınıfortamında toplanmıştır. Vefikuluçay (2008) tarafından geliştirilen YATÖ, yaşlının yaşamın sınırlama (9 madde), yaşlıya yönelik olumlu ayrimcılık (8 madde) ve yaşliya yönelik olumsuz ayrımcilık (6 madde) olmak üzere üç alt boyutu olan beşli likert tipi bir ölçektir. Ölçekten alınan toplam puan ortalamasının yüksek olması, yaşlı ayrımcılı̆̆ına ilişkin tutumun olumlu olduğunu gösterir. Araştırma öncesinde ilgili kurumdan, etik kuruldan ve öğrencilerden izin alınmıştır. Araştırmaya katılan öğrencilerin yaş ortalamasının $20.16 \pm 2.09$ (min:17, max:28) olduğu, \% 75.5'inin kadın, \% 56.2'sinin birinci sinıf ve \%45.5'inin şimdiye kadar yaşlı ile birlikte yaşadığı belirlenmiştir. YATÖ toplam puan ortalaması

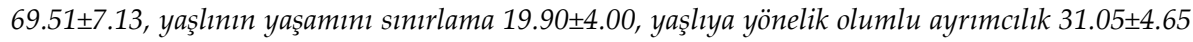
ve yaşlıya yönelik olumsuz ayrımcılık $18.55 \pm 3.59$ olarak saptanmıştır. Çalışmada birinci sımıflar ile dördüncü sımıflarm toplam ölçek puan ortalaması farkı istatistiksel olarak anlamlı bulunmuştur ( $<<0.05)$. Katılımcılarm cinsiyeti, yetiştiği sosyal çeore, gelir durumu, anne-baba eğitim durumu, yaşlı ile birlikte yaşamış olma durumuna göre ölçek puan ortalamasındaki fark istatistiksel olarak anlamlı bulunmamıştır ( $p>0.05$ ). Araştırmaya katılan öğrencilerin yaşlı ayrımcıllğına iliş̧kin orta düzeyde olumlu tutuma sahip oldukları sonucuna varılmıştır. Hemşirelik eğitimi sürecinde konuyla ilgili farkındalığın artırılmasının yaşlı sağlığına, dolayısıyla toplum sağlığına katkı sağlayacă̆ı düşünülmektedir.

Anahtar Kelimeler: Yaşlı ayrımcılı̆̆ı, Tutum, Hemşirelik öğrencisi.

OPUS @ C Uluslararası Toplum Araştırmaları Dergisi-International Journal of Society Researches ISSN:2528-9527 E-ISSN : 2528-9535

http://opusjournal.net 


\title{
Freshman and Senior Nursing Students' Attitudes Towards Elderly Discrimination
}

\begin{abstract}
This study was conducted to examine freshman and senior nursing students' attitudes towards elderly discrimination. The study which was conducted in descriptive design was carried out with 223 students in Muğla Sitkı Koçman University during November 2015-March 2016 period. The data were obtained through socio-demographic form and Elderly Discrimination Attitude Scale (YATÖ) in classrooms. The scale developed by Vefikuluçay (2008) is a 5- Likert type scale consisting limiting elderly's life (9 items), positive discrimination towards elderly (8 items), and negative attitudes towards elderly (6 items) sub dimensions. High mean value resulted from the data shows that the discrimination towards elderly is positive. Before procedure, ethical permisions were provided and students responded voluntarily. It was found that the mean value of the participant students ages was 20.16 2.09 (min:17, max:28), \% 75.5 was female, \% 56.2 was freshman students, and \%45.5 participants lived with elderly. The total scale mean value was $69.51 \pm 7.13$, limiting elderly's life mean value was $19.90 \pm 4.00$, positive discrimination towards elderly mean value was $31.05 \pm 4.65$, and negative discrimination mean value towards elderly was $18.55 \pm 3.59$ based on the analysis. There was found a statistically significant difference between freshman and senior students' total scale points $(p<0.05)$. There was not a significant difference between participants' gender, social environment, income, parents' educational background, living with an elderly and total scale points $(p>0.05)$. It was concluded that there was a middle level positive discrimination attitude towards elderly among students. Therefore, it was considered that raising awareness to the topic during nursing education would contribute to elderly's wellness, accordingly, to the public's health.
\end{abstract}

Keywords: Elderly Discrimination, Attitude, Nursing students

OPUS (c) Uluslararası Toplum Araştırmaları Dergisi-International Journal of Society Researches ISSN:2528-9527 E-ISSN : 2528-9535

http://opusjournal.net 


\section{Giriş}

Sağlık alanındaki bilimsel ve teknolojik gelişmeler, erken tanı ve tedavi yöntemlerinin uygulanması, koruyucu sağlık hizmetlerindeki gelişmeler ile sağlıkta yaşam kalitesi iyileşmekte ve buna bağlı olarak da dünyada yaşlı nüfus oranı giderek artmaktadır (Güven, Muz ve Ertürk, 2012). Dünya Sağlık Örgütü (DSÖ) yaşlılık için kronolojik tanımlamayı dikkate almakta ve bu dönemi "65 yaş ve üzeri" olarak kabul etmektedir. Türkiye İstatistik Kurumu verilerine göre ülkemizde 65 yaş ve üzeri nüfus oranı 2013 yılında \%7.7 iken, nüfus projeksiyonlarına göre bu oranın 2023 yılında \%10.2'ye, 2050 yllında \%20.8'e, 2075 yılında ise \%27.7'ye yükseleceği tahmin edilmektedir (TÜIK, 2013).

Yaşlılık, hem gelişmiş hem de gelişmekte olan ülkelerde ortalama yaşam süresinin uzamasına paralel olarak hem belli bir grup insan kitlesini oluşturmak açısından hem de belli yaşlarda daha çok ortaya çıkan hastalıklara bağlı olarak ciddi bir halk sağlığı uğraşı alanı ve problemi haline gelmiştir (Altay ve Aydın, 2015). Genelde yaşlı bireyler üretken olmamaları ve artan sağlık sorunları nedeniyle içinde yaşadıkları toplum tarafından bağımlı bir grup ve topluma yük olarak görülmektedir (Gething vd., 2004). Özellikle, yaşlıların aile ve yakın çevre tarafından sağlanan sosyal destek, yaşlanma sürecine uyum, yeterli gelir elde etme, emeklilik ve barınma gibi alanlarda da sorunlar yaşayabileceği belirtilmektedir (Akgün, Bakar, Budakoğlu , 2004). Yaşlı bireylerin tüm bu sorunlarla karşılaşmasının toplumsal ve sosyal bir sonucu olarak yaşlı ayrımcılığı ortaya çıkmaktadır.

Yaşlı ayrımcılığ terimini ilk defa 1969 yılında Amerika Ulusal Yaşlılık Enstitüsü başkanı Robert Butler kullanmıştır. Butler yaşlı ayrımcılığını; yaşlı insanlara yönelik bir ayrımcılık, ırk ayrımcılığı ve cinsiyet ayrımcılığı gibi eyleme dönüşebilen bir ideoloji türü olarak tanımlamıştır (Özdemir ve Bilgili, 2014). Palmore (2004) ise yaşlı ayrımcılığını; ileri yaştaki bireylere yönelik önyargıyı, tutum ve davranışlar aracılığı ile ifade eden bir terim olarak tanımlamıştır. Yaşlı ayrımcılığı bir kişiye sadece yaşı nedeniyle gösterilen farklı tavır, önyargı, davranış ve eylemleri içinde barındıran çok boyutlu bir terimdir (Palmore, 2004). Toplumların sosyo-kültürel yapıları ve gelenekleri, değişik alanlardaki tutum ve davranışlarını büyük 
ölçüde belirlemekte ve bu anlamda yaşlıya karşı tutum ve davranışların oluşmasında rol oynamaktadır (Altay ve Aydın, 2015; Ünsar vd. 2015).

Son yıllarda sağlık bakım hizmetinin sunulduğu tüm alanlarda yaşlı insanlara yönelik ayrımcılık yapıldığı görüşü yaygındır (Karadağ, İnkaya, Karatay, 2012). Sağlık personelinin yaşlılara yönelik kendi ön yargıları, değerleri, algılamaları, inançları yaşlı ayrımclığının temel nedenleri arasında düşünülmektedir. Yapılan çalışmalarda hemşirelerin daha genç yaş grupları ile çalışmayı tercih ettikleri, yaşlı bireylerin sorunlarını yaşamın doğal bir seyri olarak düşünüp önemsemedikleri ya da erteledikleri ve yaşlıları bağımlı, inaktif, izole olarak algıladıkları tespit edilmiştir. Akut bakım hemşirelerinin yaşlı hastalara yönelik olumlu ve olumsuz davranışlarının incelendiği bir araştırmada; hemşirelerin yaşlı ayrımclığına ilişkin olumsuz davranış sergiledikleri ve yaşlı bakımı konusunda bilgi eksikliğinin olduğu ve yaşlıların bakım kalitesinin etkilendiği belirtilmiştir (Özdemir ve Bilgili, 2014).

Sağlık bakım ekibi içinde yer alan hemşirelerin temel amaçlarından biri bireyin, ailenin ve toplumun ihtiyaç duyduğu konularda eğitim ve danışmanlık hizmeti vermektir. Toplumun yaşlı ayrımcılığına ilişkin eşitlikçi bakış açısı kazanabilmesi, kendi düşünce, davranış ve tutumlarını geliştirebilmesi için hemşirelerin rehberliğine gereksinim vardır (Vefikuluçay ve Terzioğlu, 2011). Gelecekte sağlık bakım ekibi içinde yer alacak olan hemşirelik öğrencilerinin topluma rehberlik ederken ve yaşlı bireylere sağlık bakım hizmeti sunarken, olumlu tutum içinde olmaları herhangi bir şekilde ayrımcılık sergilememeleri, yaşlılık dönemi ile ilgili yeterli bilgiye sahip olmaları bu açıdan önemlidir. Hemşirelik eğitimi veren kurumlara, hemşirelik öğrencilerinin yaşlanma ve yaşlılığa yönelik olumlu tutumlar geliştirmelerini sağlamak üzere önemli görevler düşmektedir.

Literatürde hemşirelik öğrencilerinin yaşlı bireylere karşı olumlu tutumlara sahip olduklarını gösteren çalışmalar vardır (Altay ve Aydın, 2015; Güven vd., 2012; Karadağ vd., 2012; Ünsar vd., 2015; Y1lmaz ve Özkan, 2010). Bir toplumda yaşlılara karşı olumlu tutum sergilenmesi, yaşlıların aldığı her tür hizmetin kalitesini arttıracak ve özellikle sağlık sorunlarının sık ve yoğun yaşandığı bu dönemde sağlık bakım hizmetlerinin de kalitesini olumlu yönde etkileyecektir. O nedenle ileride sağlık bakım ekibi içinde yer alacak hemşirelik öğrencilerinin, yaşlı 
ayrımclığına ilişkin tutumlarının belirlenmesi, konuyla ilgili farkındalık oluşturulması, yaşlılık ve yaşlanmaya ilişkin daha olumlu, saygılı ve hoşgörülü tutum geliştirmelerinin sağlanması önemlidir.

$\mathrm{Bu}$ araştırma, hemşirelik 1. ve 4. sınıf öğrencilerinin yaşlı ayrımcılığına ilişkin tutumlarının incelenmesi amacıyla yapılmıştır.

\section{Yöntem}

\section{Araştırmanın deseni}

Tanımlayıcı tipte tasarlanan bu araştırma, Kasım 2015-Mart 2016 tarihlerinde, Muğla Sıtkı Koçman Üniversitesi, Sağlık Bilimleri Fakültesi Hemşirelik Bölümü'nde gerçekleştirilmiştir.

\section{Evren ve Örneklem}

Araştırmanın evrenini, Hemşirelik Bölümü 1. ve 4. sınıfta öğrenim gören öğrenciler oluşturmuş, örneklem seçilmeyerek öğrencilerinin tümüne ulaşılması hedeflenmiştir. Ancak veri toplama aşamasında sınıf ortamında bulunan ve çalışmaya gönüllü katılan 233 öğrenciye ulaşılmıştır (Katılım oranı \%63.66).

\section{Veri Toplama Araçları}

Veriler sosyo-demografik form ve Yaşlı Ayrımcılığı Tutum Ölçeği (YATÖ) ile araştırmacılar tarafından toplanmıştır.

Sosyo-demografik form. Konuya ilişkin literatür incelenerek, öğrencilerin sosyo-demografik özelliklerini belirlemeye yönelik soruların yanısıra, yaşlı/yaşlılar ile yaşamaya ilişkin deneyimleri ve ileride yaşlılar ile çalışmaya bakış açısına yönelik sorulara da yer verilmiştir (Altay ve Aydın, 2015; Ünsar vd., 2015).

Yaşlı Ayrımcılı̆̆ı Tutum Ölçeği (YATÖ). Yaşlının yaşamını sınırlama, yaşlıya yönelik olumlu ayrımcllık ve yaşlıya yönelik olumsuz ayrımcilık konularını içeren üç alt boyutlu, 23 maddeden oluşan bir ölçektir. YATÖ, 
Vefikuluçay tarafından 2008 yılında geliştirilmiş ve geçerlilik-güvenirlilik (cronbach alfa güvenirlik katsayısı 0.80) çalışması yapılmıştır. Ölçek yaşlıya ilişkin ifadelerin yer aldığı her madde için "kesinlikle katılmıorum", "katılmıyorum", "kararsızım", "katılıyorum", "tamamen katılıyorum" seçenekleri olan 5'li likert tipi bir ölçektir. Ölçekte yaşlı ayrımcllığına ilişkin olumlu tutum cümlelerine; tamamen katılıyorsa " 5 " puan, katıliyorsa " 4 " puan, kararsizsa " 3 " puan, katılmiyorsa " 2 " puan, kesinlikle katılmıyorsa "1" puan alacak şekilde puanlandırılmıştır. Yaşlı ayrımcllığına ilişkin olumsuz tutum cümleleri ise; tamamen katılıyorsa "1" puan, katıliyorsa "2" puan, kararsizsa "3" puan, katilmiyorsa "4" puan, kesinlikle katılmıyorsa "5" puan alacak şekilde puanlandırılmıştır. Ölçekten alabilecekleri maksimum puan " 115 ", minimum puan ise “23"dür. Ölçekten alınan puan arttıkça yaşlı ayrımcılığına ilişkin olumlu tutum da artmaktadır. Yaşlı Ayrımcılığı Tutum Ölçeği üç boyuttan oluşmaktadır. Bunlar;

1. Yaşlının Yaşamını Sınırlama: Toplumun yaşlı bireyin sosyal yaşamını sınırlamaya ilişkin inanç ve algılarıdır. Bu boyuttan alınabilecek maksimum puan " 45 ", minimum puan ise "9" dur.

2. Yaşlıya Yönelik Olumlu Ayrımcllık: Toplumun yaşlı bireye yönelik olumlu inanç ve algılarıdır. Bu boyuttan alınabilecek maksimum puan " 40 ", minimum puan ise " 8 " dir.

3. Yaşlıya Yönelik Olumsuz Ayrımcılık: Toplumun yaşlı bireye yönelik olumsuz inanç ve algılarıdır. Bu boyuttan alınabilecek maksimum puan “30", minimum puan ise "6" dır (Vefikuluçay ve Terzioğlu 2011).

\section{Verilerin Analizi}

Veriler SPSS 20.00 paket programında değerlendirilmiştir. Verilerin normal dağılıma uygunluğu için Kolmogorov-Smirnov testi kullanılmış ve normal dağılım göstermediği belirlenmiştir ( $\mathrm{p}=0.026$ ). Tanımlayıcı istatistikler (sayı, yüzde, ortalama, standart sapma) ve nonparametrik teslerden (Kruskall-Wallis Testi, Mann-Whitney U Testi) yararlanılmıştır. Öğrencilerin sosyo-demogrofik özellikleri bağımsız değişken; YATÖ puan ortalaması ise bağımlı değişken olarak ele alınmıştır. 


\section{Araştırmanın Etiği}

Araştırma öncesinde araştırmanın yapıldığı kurumdan, etik kuruldan ve öğrencilerden izin alınmıştır.

\section{Bulgular}

Araştırma kapsamına alınan öğrencilerin yaş ortalaması 20.16 $\pm 2.09^{\prime}$ dur. Öğrencilerin \%56.2'sinin birinci sınıf öğrencisi, \%75.5'nin kız öğrenci ve \%71.7'sinin kent merkezinde yaşadığı belirlenmiştir. Araştırmaya katılan öğrencilerin \%45.5'inin 65 yaş ve üzeri yaşlı/yaşlılarla birlikte aynı evde yaşadığı, \%63.1'inin mezun olduktan sonra yaşlı bireylerle çalışmak istediği saptanmıştır (Tablo 1).

Tablo 1. Öğrencilerin Tanımlayıcı Özellikleri ( $n=233)$

\begin{tabular}{|c|c|c|c|}
\hline Değişkenler & Özellikler & $\mathbf{n}$ & $\%$ \\
\hline Yaş (min-max: 17-28) & Ort. $\pm S S: 20.16 \pm 2.09$ & & \\
\hline \multirow{2}{*}{ Sinif } & 1. Sinif & 131 & 56.2 \\
\hline & 4. Sinif & 102 & 43.8 \\
\hline \multirow{2}{*}{ Cinsiyet } & Kadın & 176 & 75.5 \\
\hline & Erkek & 57 & 24.5 \\
\hline \multirow{3}{*}{ Yetiştiği sosyal çevre } & Kent & 167 & 71.7 \\
\hline & Kırsal & 66 & 28.3 \\
\hline & Gelir giderden az & 47 & 20.2 \\
\hline \multirow[t]{3}{*}{ Aile gelir durumu } & Gelir gidere denk & 155 & 66.5 \\
\hline & Gelir giderden fazla & 31 & 13.3 \\
\hline & İlköğretim & 114 & 48.9 \\
\hline \multirow[t]{3}{*}{ Baba eğitim durumu } & Ortaöğretim & 77 & 33.0 \\
\hline & Yükseköğretim & 34 & 14.6 \\
\hline & İlköğretim & 151 & 64.8 \\
\hline \multirow{2}{*}{ Anne eğitim durumu } & Ortaöğretim & 55 & 23.6 \\
\hline & Yükseköğretim & 11 & 4.7 \\
\hline \multirow{4}{*}{$\begin{array}{l}\text { Yaşlı/yaşlılar ile birlikte aynı } \\
\text { evde yaşama durumu } \\
\text { Mezun olduktan sonra yaşlı } \\
\text { bireylerle çalışma isteği }\end{array}$} & Evet & 106 & 45.5 \\
\hline & Hayır & 127 & 54.5 \\
\hline & Evet & 147 & 63.1 \\
\hline & Hayır & 86 & 36.9 \\
\hline
\end{tabular}

Araştırmaya katılan öğrencilerin YATÖ toplam puan ortalaması 69.51 \pm 7.13 , yaşlının yaşamını sınırlama $19.90 \pm 4.00$, yaşlıya yönelik olumlu 
ayrımclık $31.05 \pm 4.65$ ve yaşlıya yönelik olumsuz ayrımcllık alt boyut puan ortalaması18.55₫3.59 olarak saptanmıştır (Tablo 2).

Tablo 2. Yaşlı Ayrımcılığı Tutum Ölçeği (YATÖ) Puan Ortalamaları

\begin{tabular}{lcc}
\hline YATÖ/alt boyutları & Ort $\pm S S$ & Min-Max \\
\hline Yaşlının Yaşamını Sınırlama & $19.90 \pm 4.00$ & $10.00-35.00$ \\
Yaşlıya Yönelik Olumlu Ayrımcılık & $31.05 \pm 4.65$ & $10.00-40.00$ \\
Yaşlıya Yönelik Olumsuz Ayrımcılık & $18.55 \pm 3.59$ & $6.00-30.00$ \\
YATÖ Toplam Puan & $69.51 \pm 7.13$, & $41.00-90.00$ \\
\hline
\end{tabular}

Öğrencilerin sinıflarına göre YATÖ puan ortalamaları karşılaştırıldığında, 1.sınıf öğrencilerin puanlarının 4.sınıf öğrencilerin puanlarına göre daha yüksek olduğu belirlenmiştir. Bu farkın istatiksel olarak anlamlı olduğu saptanmıştır ( $Z=5094.500, \mathbf{p}=\mathbf{0 . 0 0 2}$ ) (Tablo 3).

Tablo 3. Öğrencilerin Sınıflarına Göre YATÖ Puan Ortalamasının Dă̆ılımı

\begin{tabular}{llllll}
\hline Sinif & $\mathbf{n}$ & $\overline{\mathbf{X}}$ & ss & $\mathbf{Z}$ & $\mathbf{p}$ \\
\hline 1. Sinif & 131 & 70.80 & 7.33 & & \\
4. sinif & 102 & 67.85 & 6.53 & 5094.500 & $\mathbf{0 . 0 0 2}$ \\
\hline
\end{tabular}

Z= Mann-Whitney U Test

Öğrencilerin cinsiyetlerine göre YATÖ puan ortalamaları karşılaştırıldığında, erkek öğrencilerin puanlarının kız öğrencilerin puanlarına göre daha yüksek olduğu belirlenmiş ancak bu farkın istatiksel olarak anlamsız olduğu saptanmıştır ( $\mathrm{Z}=4705.000, \mathrm{p}=0.481)$ (Tablo 4).

Tablo 4. Öğrencilerin Cinsiyetine Göre YATÖ Puan Ortalamasının Dă̆ılımı

\begin{tabular}{lrllll}
\hline Cinsiyet & $\mathbf{n}$ & $\overline{\mathbf{X}}$ & ss & $\mathbf{Z}$ & $\mathbf{p}$ \\
\hline Kadın & 176 & 69.44 & 6.90 & & \\
Erkek & 57 & 69.73 & 7.84 & 4705.000 & 0.481 \\
\hline
\end{tabular}

Z= Mann-Whitney U Test

Öğrencilerin yetiştiği sosyal çevreye göre YATÖ puan ortalamaları karşılaştırıldığında, kırsalda yaşayan öğrencilerin puanlarının kentte yaşayan öğrencilerin puanlarına göre daha yüksek olduğu belirlenmiştir. $\mathrm{Bu}$ farkın istatiksel olarak anlamsız olduğu saptanmıştır $(\mathrm{Z}=5360.000$, $\mathrm{p}=0.744)$ (Tablo 5). 
Tablo 5. Öğrencilerin Yetiştiği Sosyal Çevreye Göre YATÖ Puan Ortalamasının Dağılımı

\begin{tabular}{llllll}
\hline Sosyal Çevre & $\mathbf{n}$ & $\overline{\mathbf{X}}$ & ss & $\mathbf{Z}$ & $\mathbf{p}$ \\
\hline Kent & 167 & 69.44 & 7.46 & & \\
Kırsal & 66 & 69.68 & 6.26 & 5360.000 & 0.744 \\
\hline
\end{tabular}

Z= Mann-Whitney U Test

Öğrencilerin aile gelir durumuna göre YATÖ puan ortalamaları karşılaştırıldığında, geliri giderinden az olan öğrencilerin ailelerinin puanlarının gelir gidere denk ve gelir giderden fazla olan öğrencilerin ailelerinin puanlarına göre daha yüksek olduğu belirlenmiştir. Bu farkın istatiksel olarak anlamsız olduğu saptanmıştır $(\mathrm{KW}=2.292$, p=0.318) (Tablo 6).

Tablo 6. Aile Gelir Durumuna Göre YATÖ Puan Ortalamasının Dă̆ılımı

\begin{tabular}{lrllll}
\hline Aile gelir Durumu & $\mathbf{n}$ & $\overline{\mathbf{X}}$ & ss & KW & p \\
\hline Gelir giderden az & 47 & 70.72 & 8.00 & & \\
Gelir Gidere denk & 155 & 69.37 & 7.06 & 2.292 & 0.318 \\
Gelir Giderden fazla & 31 & 68.38 & 5.91 & & \\
\hline
\end{tabular}

KW=Kruskal-Wallis Test

Anne-baba eğitim durumu ve yaşlı ile birlikte yaşamış olma durumuna göre de öğrencilerin ölçek puan ortalamalarında anlamlı fark bulunmamıştır ( $p>0.05)$.

\section{Tartışma}

Yaşlı ayrımcılığında, kişisel, kültürel ve yapısal düzey olmak üzere üç düzeyden bahsedilmektedir. Kişisel düzeyde bireyin yaş ve yaşlanmaya ilişkin bakış açısı belirleyicidir ve bu büyük ölçüde bireyin içinde yetiştiği, sosyalleştiği ve öğrendiği yaşlılığa ilişkin kabullerle ilgilidir. Kültürel düzeyde kültürün yaşlıya bakışı, bunun görsel ve yazılı medyayla nasıl sunulduğu, yaşlılıkla ilgili şakalar, küçük düşürücü espriler, atıflar vb. belirleyicidir. Yapısal düzeyde ise kurumların ya da politikaların yaşlılara yönelik olarak yapılanmaması, hizmet sunmaması ya da yetersiz hizmet sunumu, adil olmayan politikalar ve hizmetler anlaşılmaktadır (Buz, 2015). 
$\mathrm{Bu}$ araştırmada YATÖ kullanılarak hemşirelik öğrencilerinin yaşlı ayrımcılığına ilişkin tutumları değerlendirilmiş (YATÖ toplam puan ortalaması 69.51 \pm 7.13) ve genel olarak tutumlarının olumlu yönde olduğu saptanmıştır. Benzer çalışmalarda da öğrencilerin yaşlı ayrımcılığına ilişkin tutumlarının olumlu yönde olduğu bildirilmektedir (Altay ve Aydın, 2015; Güven vd., 2012; Karadağ vd., 2012; Ünsar vd., 2015; Yılmaz ve Özkan, 2010). Kite, Stockdale, Whitley, Johnson (2005) tarafından yapılan çalışmada ise gençlerin yaşlı bireylere yönelik tutumlarının olumsuz olduğu saptanmıştır. Bu farklılı̆̆ın nedeni, kültürler arasında yaşlı ve yaşlıya karşı inançların ve tutumların değişkenlik göstermesi olabilir.

Bu çalışmada, öğrencilerin yaşlının yaşamını sınırlama alt boyut puan

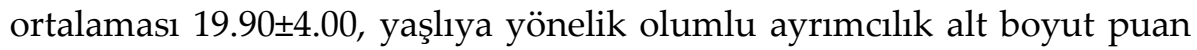
ortalaması $31.05 \pm 4.65$, yaşlıya yönelik olumsuz ayrımcılık alt boyut puan ortalaması 18.55 3.59 olarak belirlenmiştir. Özellikle yaşlıya yönelik olumlu ayrımcılık puan ortalamasının yüksek olması dikkat çekicidir ve olumlu değerlendirilebilir. Araştırmada, öğrencilerin yaklaşık yarısının (\% 45.5) hayatının herhangi bir döneminde, aile içinde, yaşlı bireyle yaşamış olması da yaşlılara yönelik olumlu tutuma sahip olmalarının bir nedeni olabilir. Modernleşen dünya ve değişen yaşam koşullarına rağmen kültürümüzde var olan yaşlıya saygı, bilgi ve deneyimlerine değer verme gibi özelliklerimizin halen devam etmesi sevindiricidir. Altay ve Aydın'ın (2015) hemşirelik öğrencilerinin yaşlı bireylere karşı tutumunu incelediği çalışmada da benzer şekilde, öğrencilerin YATÖ toplam puan ortalamaları 68.82 \pm 8.54 , yaşlının yaşamını sınırlama alt boyut puan ortalaması $22.41 \pm 5.49$, yaşlıya yönelik olumlu ayrımcılık alt boyut puan ortalaması $28.82 \pm 5.44$ ve olumsuz ayrımcilık puan ortalaması $17.57 \pm 3.46$ olarak bulunmuştur.

$\mathrm{Bu}$ çalışmada kız öğrencilerin YATÖ puan ortalamalarının erkek öğrencilere göre daha düşük olduğu bulunmakla birlikte gruplar arasında anlamlı bir fark olmadığı görülmüştür. Çalışmanın bulgusu bazı literatür (Koç, Yıldırım, Gürcü, Uluçay, 2013; Soyuer, Ünalan, Güleser, Elmalı, 2010; Ünalan vd., 2012; Ünsar vd., 2015) bulguları ile benzerlik gösterirken, bazıları (Altay ve Aydın, 2015; Güven ve ark. 2012) ile farklılık göstermektedir. Cinsiyet faktörünün yaşlı ayrımcılığı ile ilgili tutumlarda etkili olduğunu gösteren çalışmalarda, bu farkın 
kültürümüzdeki kadının bakım verici rolünden kaynaklanabileceği düşünülmektedir.

Çalışmada birinci sınıf öğrencilerin YATÖ puan ortalamalarının dördüncü sınıflardan daha yüksek olduğu ve farkın istatiksel olarak anlamlı olduğu saptanmıştır. Çalışmanın bulgusu literatür bulguları ile farklılık göstermektedir (Altay ve Aydın, 2015; Kulakçı, 2010; Yılmaz ve Özkan, 2010; Vefikuluçay ve Terzioğlu, 2011). Oysa öğrenim düzeyi arttıkça hemşirelik öğrencilerinin yaşlı ayrımcılığına ilişkin tutumlarının olumlu yönde değişmesi beklenir.

Araştırma kapsamına alınan öğrencilerin yetiştiği sosyal çevreye göre YATÖ puan ortalamaları karşılaştırıldığında kırsalda yaşayan öğrencilerin puanlarının kentte yaşayan öğrencilerin puanlarına göre daha yüksek olduğu belirlenmiştir. Ancak bu farkın istatiksel olarak anlamsız olduğu saptanmıştır. Benzer şekilde Soyuer vd. (2010) çalışmasında, yaşanılan yerin yaşlıya yönelik ayrımcılık tutumlarında etkisiz olduğu vurgulanmıştır. Yılmaz ve Özkan (2010) ise çalışmalarında, köy/ kasaba gibi yerleşim yerlerinde doğan öğrencilerin olumlu ayrımcllı puan ortalamalarının daha yüksek olduğunu belirtmişlerdir.

Çalışmada öğrencilerin genel olarak yaşlıya yönelik olumlu tutuma sahip oldukları belirlenmesine rağmen, \%36.9'unun mezun olduktan sonra yaşlı bireyler ile çalışmak istemedikleri dikkat çekmiştir. Bu oran Ünsar vd. (2015) çalışmasında \%52, Altay ve Aydın'ın (2015) araştırmasında \%36.9 olarak bildirilmiştir.

\section{Sonuç ve Öneriler}

Hemşirelik öğrencilerinin genel olarak yaşlıya yönelik olumlu tutuma sahip oldukları saptanmıştır. Hemşirelik lisans eğitiminde, yaşlılık, yaşlanma süreci ve yaşlı bakımına ilişkin konuların daha ayrıntılı yer alması, öğrencilere yaşlı kliniklerinde, huzurevi ve rehabilitasyon merkezi gibi kurumlarda uygulama yapma fırsatı verilmesi, geriatri hemşireliği becerilerini geliştirme ve yaşlı ayrımcılığının önlenmesi açısından yararlı olabilir. 


\title{
EXTENDED ABSTRACT
}

\section{The Effect of Psychoeducation Program for Reducing Lonelinesson Loneliness Level of The Elderly}

\author{
Alihan Olak / Adile Tümer \\ Kartal Koşuyolu YİEAH / Muğla Sıtkı Koçman University
}

Definition and Importance: As in the world, elderly population in Turkey is also increasing. Aging is inevitable physiologically. Aging is a process of diminishing productivity, competency, individuality and independence in all life activities. Elderly discrimination is a multidimensional term including different attitudes, prejudices, behaviors, and actions towards a person only due to their age-related insufficiency and problems. The socio-cultural structures and traditions of the societies largely determine the attitudes and behaviors in different areas and plays a role in the formation of attitudes and behaviors towards the elderly. In almost every area, discrimination related to old age must be presented with scientific evidence. In recent years, there has been a growing consensus that elderly people are discriminated against in all areas where health care is provided. The prejudices, values, perceptions and beliefs of the health personnel about elderly are among the main reasons of the elderly discrimination. It has been observed that nurses prefer to work with younger age groups, they consider elderly people's problems as a natural course of life and they ignore or postpone these problems, and they perceive the elderly as dependent, inactive, and isolated. Nurses' guidance is necessary to enable society to gain an egalitarian view on age discrimination and to develop their own thinking, behavior and attitudes. It is important for the nursing students who will take part in health care team in the future to have a positive attitude, to not exhibit discrimination in any way and to have sufficient knowledge about the old age while providing guidance and health care services to elderly people. Institutions providing nursing education have important duties in the development of positive attitudes towards aging 
and old age. Positive attitudes towards the elderly in the society will increase the quality of all services provided to the elderly and affect the quality of health care services positively especially in this times where health problems are frequent and intense. For this reason, determining the attitudes of the nursing students regarding elderly discrimination, raising awareness on this subject, providing more positive, respectful, and tolerant attitudes towards old age and aging is important. Aim: This study was conducted to examine freshman and senior nursing students' attitudes towards elderly discrimination. Method: The study which was conducted in descriptive design was carried out with 223 students in Muğla Sttk1 Koçman University during November 2015-March 2016 period. The data were obtained through socio-demographic form and Elderly Discrimination Attitude Scale (YATÖ) in classrooms. The scale developed by Vefikuluçay (2008) is a 5- Likert type scale consisting limiting elderly's life (9 items), positive discrimination towards elderly (8 items), and negative attitudes towards elderly (6 items) sub dimensions. High mean value resulted from the data shows that the discrimination towards elderly is positive. Before procedure, ethical permisions were provided and students responded voluntarily. Results: It was found that the mean value of the participant students ages was $20.16 \pm 2.09$ ( $\min : 17$, max:28), \% 75.5 was female, \% 56.2 was freshman students, and \%45.5 participants lived with elderly. The total scale mean value was $69.51 \pm 7.13$, limiting elderly's life mean value was $19.90 \pm 4.00$, positive discrimination towards elderly mean value was $31.05 \pm 4.65$, and negative discrimination mean value towards elderly was $18.55 \pm 3.59$ based on the analysis. There was found a statistically significant difference between freshman and senior students' total scale points $(\mathrm{p}<0.05)$. There was not a significant difference between participants' gender, social environment, income, parents' educational background, living with an elderly and total scale points ( $p>0.05)$. Conclusion: It was concluded that there was a middle level positive discrimination attitude towards elderly among students. Therefore, it was considered that raising awareness to the topic during nursing education would contribute to elderly's wellness, accordingly, to the public's health. 


\section{Kaynakça / References}

Akgün S., Bakar C. ve Budakoğlu İ. (2004). Dünyada ve Türkiye'de yaşlı nüfus eğilimi, sorunları ve iyileştirme önerileri. Turkish Journal of Geriatrics,7(2), 105-110.

Altay B. ve Aydın T. (2015). Hemşirelik öğrencilerinin yaşlı ayrımcılığına ilişkin tutumlarının değerlendirilmesi. Hemşirelikte Eğitim Ve Araştırma Dergisi, 12(1), 11-18

Buz, S.(2015). Yaşlı bireylere yönelik yaş ayrımcılığı. Elektronik Sosyal Bilimler Dergisi, 14(53), 268-278.

Gething L., Fethney J., McKee K., Persson L.O., Goff M. ve Churchward M. (2004) Validation of the reactions to ageing questionnaire: assessing similarities across several countries. J Gerontol Nurs, 30, 4754. http://dx.doi.org/10.3928/0098-9134-20040901-09

Güven Ş.D., Muz G.U. ve Ertürk N.E. (2012) Üniversite öğrencilerinin yaşlı ayrımcılığına ilişkin tutumları ve bu tutumların bazı değişkenlerle ilişkisi. Anadolu Hemşirelik ve Sağlık Bilimleri Dergisi, 15(2), 99-105.

Karadağ E., Vardar İnkaya B. ve Karatay G. (2012). Hemşirelik öğrencilerinin yaşlı ayrımcılığına ilişkin tutumları. Ege Üniversitesi Hemşirelik Fakültesi Dergisi, 28, 31-40.

Kite M.E., Stockdale G.D., Whitley B.E., Johnson B.T. (2005) Attitudes toward younger and older adults: an updated meta-analytic review. Journal of Social Issues, 61(2), 241-266.

Koç A., Yıldırım R., Gürcü M. ve Uluçay D.V. (2013) Assessing young university students' behaviour regarding age discrimination. J Ann Eu Med 1(3), 49-55.

Özdemir Ö. ve Bilgili N. (2014) Sağlık Hizmetlerinde yaşlı ayrımcılığı. Gülhane Tip Dergisi, 56, 128-131.

Soyuer F., Ünalan D., Güleser N. ve Elmalı F. (2010) Sağlık Meslek Yüksekokulu öğrencilerinin yaşlı ayrımcllığına ilişkin tutumları ve bu tutumların bazı demografik değişkenlerle ilişkisi. Mersin Üniversitesi Să̆lık Bilimleri Dergisi, 3, 20-5.

Türkiye İstatistik Kurumu Haber Bülteni (2014) İstatistiklerle yaşlılar, 2013. Sayı: 16057. 
Ünalan D., Soyuer F. ve Elmalı F. (2012) Geriatri merkezi çalışanlarında yaşlı tutumunun değerlendirilmesi. Kafkas J Med Sci, 2(3), 115-120 - doi: $10.5505 / \mathrm{kjms} .2012 .15870$

Ünsar S., Erol Ö., Kurt S., Türüng F., Sekmen I., Sak C. ve Türksen S. (2012) Hemşirelik Öğrencilerinin Yaşlı Ayrımcılığına İlişkin Tutumlarının İncelenmesi. Cumhuriyet Hemşirelik Dergisi, 1, 12-13.

Vefikuluçay D. ve Terzioğlu F. (2011) Development and psychometric evaluation of ageism attitude among the university students. Turkish Journal of Geriatrics,14(3), 259-268.

Yılmaz E. ve Özkan S. (2010) Hemşirelik öğrencilerinin yaşlı ayrımcılığına ilişkin tutumları. Maltepe Üniversitesi Hemşirelik Bilim ve Sanatı Dergisi, 3, 35-53.

\section{Kaynakça Bilgisi / Citation Information}

Olak, A. ve Tümer, A. (2018). Hemşirelik 1. ve 4. sınıf öğrencilerinin yaşlı ayrımcılığına ilişkin tutumları. OPUS - Uluslararası Toplum Araştırmaları Dergisi, 8(14), 53-67. DOI: 10.26466/opus.337355 